Grishina A. V., \& Abakumova I. V. (2020). Informational behavior in the COVID-19 pandemic: psychological predictors, International Journal of Cognitive Research in Science, Engineering and Education (IJCRSEE), (8), Special issue of Current Research and Trends in Cognitive Sciences 2020, 59-67.

Original scientific paper

UDK:

Received: November, 13.2020

Revised: December, 01.2020.

Accepted: December, 06.2020.

59.944.4.072-057.875:[616.98:578.834(470)

doi: 10.23947/2334-8496-2020-8-SI-59-67

\title{
Informational Behavior in the COVID-19 Pandemic: Psychological Predictors
}

\author{
Grishina Anastasia Vasilievna ${ }^{1 *}$, Abakumova Irina Vladimirovna ${ }^{2}$
}

\begin{abstract}
${ }^{1}$ Department of General and Counseling psychology, "Psychology, pedagogy and defectology" faculty, Don State Technical University, Rostov-on-Don, Russian Federation, e-mail: abakira@mail.ru

${ }^{2}$ Corresponding Member of Russian Academy of Education, Dean of "Psychology, pedagogy and defectology" faculty, Don State Technical University, Rostov-on-Don, Russian Federation, e-mail: abakira@mail.ru
\end{abstract}

\begin{abstract}
The core problem of the COVID-19 pandemic for psychologists is to find out how people cope with the stress of isolation and the threat of fatal disease. The scale of the pandemical impact on the psychological well-being of an individual has still no knowledge and psychological predictors which the impact depends on need to be identified. This paper presents an empirical study of informational behavior and its psychological predictors in the pandemic. The research was held online in April-May 2020. The total amount of 165 participants, aged from 18 to 66 . The subjects were chosen from a randomly selected sample. The participants were asked to estimate their informational consumption in pandemic. Tolerance to ambiguity, hardiness and anxiety was studied in groups distinguished according to changes in informational consumption. The findings of this study indicate a significant correlation between informational behavior and psychological characteristics related to coping with stress. Besides the analysis proved a negative correlation between reactive and personal anxiety and tolerance to ambiguity, hardiness and its components. We have confirmed that increased informational comsumption can be considered as a coping strategy for overcoming the pandemic social isolation among respondents with low hardiness and tolerance to ambiguity. Stable and decreased informational consumption indicates that respondents with high hardiness and tolerance to ambiguity and low state and trait anxiety don't need to consume information for coping with difficulties of pandemic self-isolation. Future work will concentrate on expanding the list of psychological predictors of informational behavior and studying the features of their interaction in different situations.
\end{abstract}

Keywords: pandemic, informational behavior, tolerance to ambiguity, hardiness, anxiety.

\section{Introduction}

The coronavirus disease 2019 (COVID-19) pandemic has had a significant impact on people's psychological health and wellbeing. The behavior of a person in the pandemic situation is still poorly understood as this is the first time when the mankind faces such a global and unknown threat and takes such measures to prevent its spread. Besides, the uniqueness of this situation lies in the fact that the pandemic has affected all spheres of human life - work, leisure, nutrition, sports (Våpenstad, 2010). One of the main issues in our knowledge of COVID-19 is a lack of facts about its real origin and effects. This led all social situations to the highest level of ambiguity, causing great psychological effects both on the level of a personality and of the society.

Tolerance to ambiguity is increasingly becoming a vital factor in psychological health of a modern man. The first studies of tolerance to ambiguity considered it to be an emotional and perceptual personal variable (Frenkel-Brunswik, 1948). E. Frenkel-Brunswik describes a personality type with a high level of intolerance to uncertainty, characterized by a tendency to make decisions on the principle of black - white; to draw hasty conclusions without taking into account significant factors and the real situation; strive for unconditional acceptance or rejection irelationships with other people.

The further studies proposed a new definition of tolerance to ambiguity considering it a basic personality trait. It was included in the theory of authoritarian personality (Adorno et al., 1950) as one of the typical characteristics of an authoritarian personality, explaining its behavior.

S. Budner has put forward the psychological content of this construct and understands intolerance to ambiguity as a tendency to interpret uncertain situations as a source of threat (Budner, 1962).

"Corresponding author: avgrishina.donstu@gmail.com 
He identified the following signs of an uncertain situation:

- novelty (a completely new situation not previously encountered in experience);

- complexity (a difficult situation with a large number of variables);

- unsolvability (different elements of the situation give rise to conflicting interpretations).

Budner S. (1962) identified four indicators of individual threat perception, acting as threat experiences (phenomenological reactions) or behavior in a threat situation (operational reactions):

- phenomenological submission (discomfort),

- phenomenological denial (repression, suppression),

- operational submission (avoidant behavior)

- operational denial (destructive or reconstructive behavior).

After the ideas of first researchers, tolerance to ambiguity was understood as a tendency to interpret uncertain situations as desired. It is studied by the this group of researchers as a stable personality trait: from works of MacDonald, A. P. (1970), Hazen et al. (2012), Norton R. W. (1975), to latest researches of Herman et al. (2010), Litman (2010), Zhu, D., Xie, X., and Xie, J. (2012).

Other authors consider tolerance to ambiguity as a dynamic personal characterictic, that can advance during professional education (DeRoma, Martin and Kessler, 2003) and psychotherapy (Våpenstad, 2010). Kajs L. T. and McCollum D. L. point out that tolerance to ambiguity can increase with extension of life experience and age (Kajs and McCollum, 2010).

Tolerance to ambiguity has received much attention from scientists in the last 20 years. It has become a significant value for a modern man, helping to adapt to the constantly changing world.

The ideas of S. Maddi can be used as a starting point in studying COVID-19 pandemic as a situation of revealing hardiness. S. Maddi has proposed a new definition of personality hardiness as the personality pattern of attitudes and strategies that helps people turn stressful circumstances from potential disasters into growth opportunities. It's a composite of the interrelated attitudes of commitment, control and challenge that together provide the existential courage (Maddi, 2015).

People who are strong in commitment attitude get involved with what is happening, regardless of how stressful it may seem, perceiving this as the best way to learn from their experiences. People who are strong in the controlling attitude believe that trying to influence outcomes by the decisions they make is more likely to lead to meaningful outcomes then sinking into powerlessness in the face of stress. People who are strong in the challenging attitude believe that stress is normal and fulfillment is not to be found in easy comfort, security, and routine but rather in the continual growth in wisdom through what is learned from the negative and positive experiences of an active, changing life (Maddi et al., 2011).

D.A.Leontiev considers the phenomenon of hardiness in the context of personal potential and defines hardiness as an integrative characteristic of a person responsible for success in overcoming a person's various life difficulties (Leontiev et al., 2011; Leontiev, 2019).

Further researchers have focused on place of hardiness in personality structure and its correlation with other psychological constructs: the connection of hardiness with an identity crisis (Kuzmin, Gusev, and Konopak, 2010), with personal-situational interaction, with psychological content of the students' personality vitality (Loginova, 2010; Soboleva and Shumakova, 2014).

The phenomenon of anxiety is the subject of comprehensive psychological research. In this work we rely on K. Spilberger's approach to anxiety. He distinguishes anxiety as a state (reactive anxiety) and anxiety as a trait (personal anxiety). Reactive anxiety is temporary emotional state caused by the action of real or imaginary danger to the individual. Personal anxiety is a stable individual property, determined by the tendency of the subject to perceive a threat to his own personality and the willingness to respond to the threat with an increase in reactive anxiety in situation of even a small danger or stress (Spielberger, 1972).

Cognitive psychology focuses on anxiety influence on cognitive processes. It was found that high level of anxiety makes the person focus his attention on objects and facts related to the reason of anxiety or on information that can help to overcome stress and reestablish the psychological well-being.

\section{Materials and Methods}

Our research aimed to analyze the psychological predictors of infromational behaviour in the pandemic situation. This paper calls into a question if the informational behavior strategies can be considered as a coping strategies in the situation of social isolation.

Subjects were chosen from a randomly selected sample of working and not-working citizens of Rostov-on-Don aged from 18 to 66. The research was held online in April-May 2020 (from 48 to 60 days 
Grishina A. V., \& Abakumova I. V. (2020). Informational behavior in the COVID-19 pandemic: psychological predictors, International Journal of Cognitive Research in Science, Engineering and Education (IJCRSEE), (8), Special issue of Current Research and Trends in Cognitive Sciences 2020, 59-67.

of lockdown mode in Rostov-on-Don, Russia). All study participants were asked to fill out identical forms for testing and questioning. The total amount of 165 participants included 55 men and 110 women. predictors.

The hypothesis of the study: informational behavior in pandemic situation can have psyhological

To the group of such predictors the following psychological characteristics were chosen:

- hardiness

- tolerance to ambiguity

- anxiety as a state

- anxiety as a trait

To prove our hypothesis the following methods were chosen:

- MacLane's Uncertainty Tolerance Scale (MSTAT-I) (adapted by E. G. Lukovitskaya)

-The Personal Views Survey III-R by S. R. Maddi (adapted by D. A. Leontiev, E. I. Rasskazova)

- State-Trait Anxiety Inventory (STAI ) by Ch. D. Spielberger (adapted by Yu. L. Khanin)

- Authors' questionnaire on studying changes in informational behavior of respondents during COVID-19 social isolation.

The questionnaire contained questions about how many hours a day respondents were consuming different types of content (news, political TV-shows, Internet blogs, documentaries, movies, serials, social networks) before the pandemic situation, how many hours a day they where planning to consume the described content in the pandemic isolation (when it only began) and how it turned up in the reality of social isolation.

Statistical methods of data processing: to identify the probabilistic relationship of indicators, we used the Spearman rank order correlation coefficient; to determine the significance of differences in the subgroups, we used the non-parametric Kruskal-Wallis test.

\section{Results}

Our aim was to get a general picture of psychological predictors of informational behavior. To define different informational behavior strategies we used our questionnaire. In response to the question «Has your informational consumption changed in COVID-19 pandemic?» the respondents estimated the time they had been spending on the listed types of content before the pandemic, in plans for pandemic and over the course of the pandemic. It allowed us to devide all respondents into 3 groups:

Group 1. Increased informational consumption - 80 respondents

Group 2. Stable informational consumption - 65 respondents

Group 3. Decreased informational consumption- 20 respondents.

The next step was therefore to investigate the differences in the psychological characteristics of the distinguished groups.

The level of tolerance to uncertainty has significant differences in the groups (Fig.1).

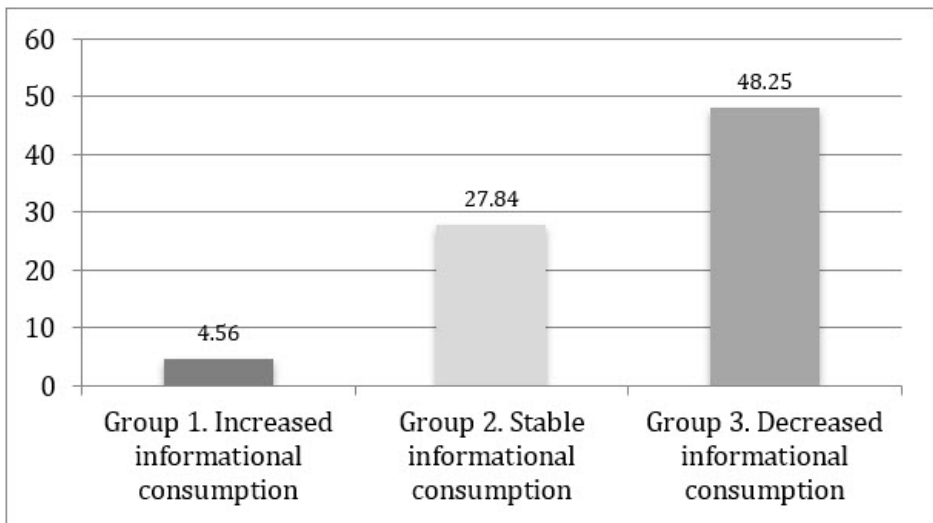

Figure 1. Tolerance to ambiguity in groups with different informational consumption

The average score of tolerance to ambiguity for the Group 1 Increased Informational Consumption is the lowest for the sample. Many respondents of this group showed even negative scores. It indicates that these respondents feel uncomfortable in ambiguous situations. They feel afraid of uncertainty and 
usually hide from solving serious problems. The respondents from Group 3 Decreased Informational Consumption showed the highest level of tolerance to ambiguity. They can be characterized as creative people aware of the complexity and unpredictability of the world and are ready to adapt to it. Group 2 Stable Informational Consumption has medium positive scores of tolerance to ambiguity.

Thus, the increased informational consumption can be defined as a strategy of overcoming uncertainty in the COVID-19 pandemic for Group 1. The qualitative analysis of answers on the authors' questionnaire in this group showed the increase of the consumption of the content, primarily related to the cause of the pandemic: news, political TV-shows, and documentaries. Probably, finding the latest information on pandemic and social isolation allowed these respondents to feel more confident and to understand better the prospects for the development of the social situation.

The level of hardiness and its components has also differences in the groups (Fig. 2).

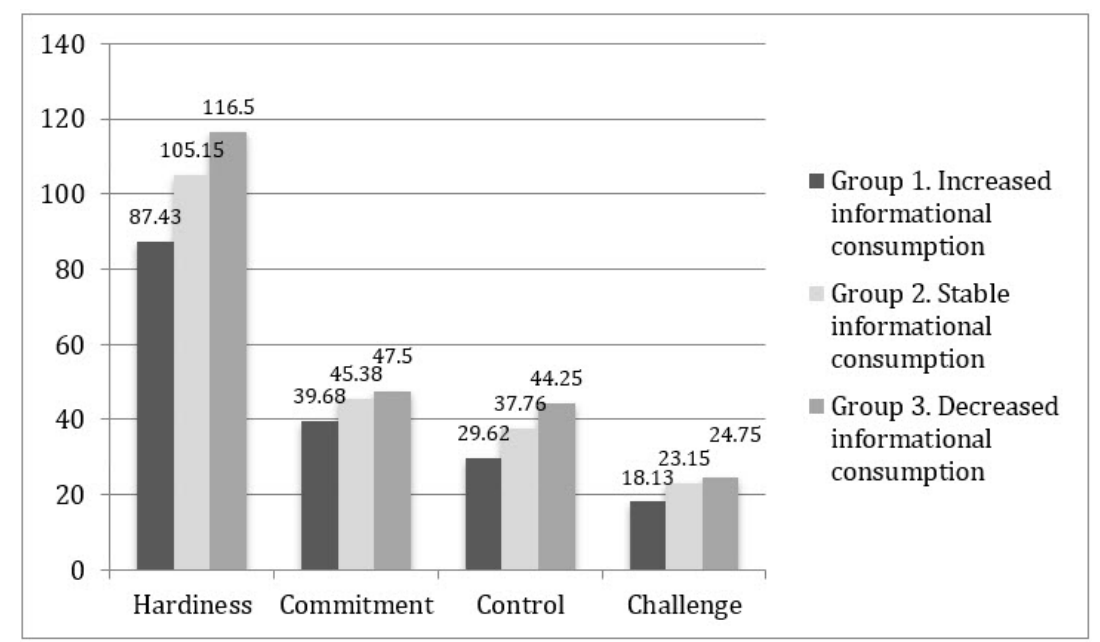

Figure 2. Hardiness and its components in groups with different informational consumption

The average score in hardiness and its components (commitment, control, challenge) for the Group 1 Increased Informational Consumption is also lowest for the sample, but can be rated as standard compared to regulatory values. The respondents from Group 3 Decreased Informational Consumption showed the highest level of hardiness, commitment, control and challenge.

Hardiness is a system of personal beliefs that allows personality to overcome anxiety in situations of uncertainty and to be independent of situational emotional reactions. In this context the highest level of hardiness in Group 3 reveals their psychological and behavior skills in difficult situations such as social exclusion and pandemic:

- high scores on Commitment scale indicate the belief that involvement in what is happening in pandemic gives the maximum chance of finding worthwhile information and making the right decisions;

- high level of Control reflects the confidence that one's actions can influence the outcome of what is happening in the pandemic;

- high scores in Challenge scale shows a willingness to accept the positive and negative experience of social isolation, finding a source of new knowledge and experience in it.

These results correlate with answers of Group 3 about positive and negative experiences of selfisolation in the pandemic: "I pay more attention to the family", "I do sports at home", "I can just relax", "I study new courses and webinars".

The level of anxiety has also differences in the groups (Fig. 3). 


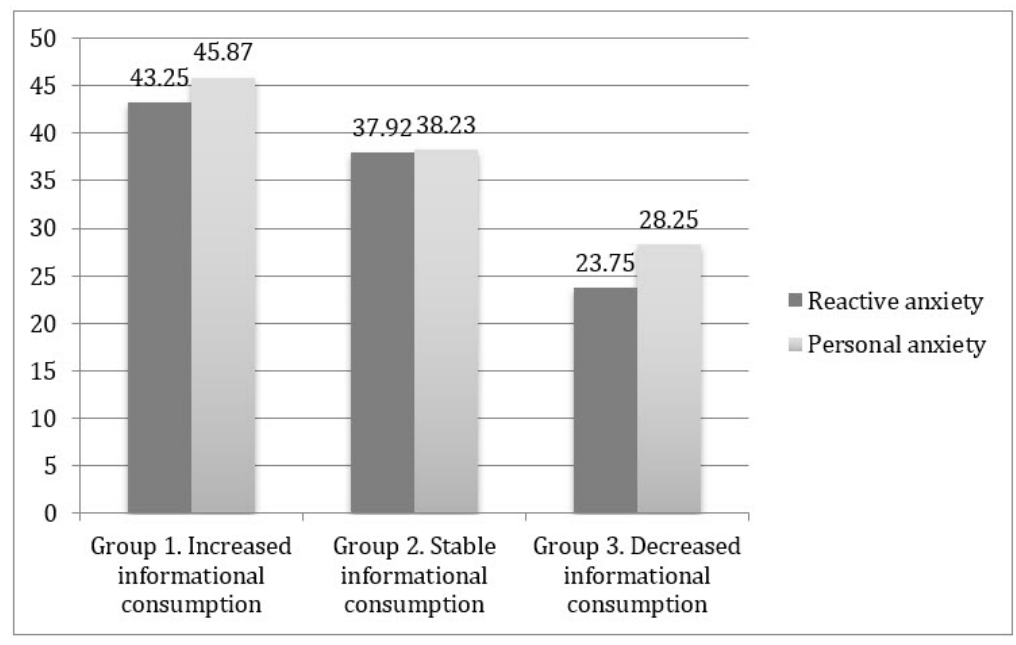

Figure 3. Level of reactive and personal anxiety in groups with different informational consumption

The level of anxiety is the highest in Group 1. The average scores in Group 3 are the lowest in the sample. Group 2 showed medium results. In all experimental groups the level of personal anxiety is insignificantly higher than situational anxiety.

In order to identify the relationship between studied indicators, we used the Spearman rank correlation coefficient (Table 1).

Table 1

Results of statistical analysys by Spearman rank order correlation coefficient

\begin{tabular}{lcc}
\hline \multicolumn{1}{c}{ Psychological predictors } & $\begin{array}{c}\text { Spearman rank order } \\
\text { correlation }\end{array}$ & p-value \\
\hline Tolerance to ambiguity \& reactive anxiety & $-0,550$ & 0,001 \\
Tolerance to ambiguity \& personal anxiety & $-0,675$ & 0,000 \\
Hardiness \& reactive anxiety & $-0,520$ & 0,002 \\
Hardiness \& personal anxiety & $-0,780$ & 0,000 \\
Commitment \& reactive anxiety & $-0,427$ & 0,013 \\
Commitment \& personal anxiety & $-0,732$ & 0,000 \\
Control \& reactive anxiety & $-0,397$ & 0,022 \\
Control \& personal anxiety & $-0,865$ & 0,000 \\
Challenge \& reactive anxiety & $-0,506$ & 0,003 \\
Challenge \& personal anxiety & $-0,516$ & 0,002 \\
\hline
\end{tabular}

The analysis proved a negative correlation between reactive and personal anxiety and tolerance to ambiguity, hardiness and its components (commitment, control, challenge): in all studied groups the higher is anxiety the lower are the levels of other studied characteristics.

The next step was to determine the significance of differences in the subgroups, using nonparametric Kruskal-Wallis test (Table 2). 
Grishina A. V., \& Abakumova I. V. (2020). Informational behavior in the COVID-19 pandemic: psychological predictors, International Journal of Cognitive Research in Science, Engineering and Education (IJCRSEE), (8), Special issue of Current Research and Trends in Cognitive Sciences 2020, 59-67.

Table 2

Differences in the components of hardiness, the level of tolerance to ambiguity and anxiety in groups with different informational consumption

\begin{tabular}{|c|c|c|c|c|c|}
\hline \multirow[t]{2}{*}{ Variables } & \multicolumn{3}{|c|}{ Changes in informational behavior (Mean Rank) } & \multicolumn{2}{|c|}{$\begin{array}{l}\text { Significance of } \\
\text { Differences } \\
\text { (Kruskal-Wallis test) }\end{array}$} \\
\hline & $\begin{array}{c}\text { Increased } \\
\mathrm{N}=80\end{array}$ & $\begin{array}{l}\text { Stable } \\
N=65\end{array}$ & $\begin{array}{c}\text { Decreased } \\
N=20\end{array}$ & H & p \\
\hline \multicolumn{6}{|c|}{ Ambiguity Tolerance Scale } \\
\hline Tolerance to ambiguity & 10,96875 & 20,69231 & 29,12500 & 14,41695 & 0,0007 \\
\hline \multicolumn{6}{|c|}{ The Personal Views Survey III-R } \\
\hline Hardiness & 11,00 & 21,15385 & 27,50 & 13,29157 & 0,0013 \\
\hline Commitment & 11,34375 & 21,65385 & 24,50 & 10,94187 & 0,0042 \\
\hline Control & 11,71875 & 20,34615 & 27,25 & 10,87155 & 0,0044 \\
\hline Challenge & 10,96875 & 21,57692 & 26,25 & 13,14260 & 0,0014 \\
\hline \multicolumn{6}{|c|}{ Scale for assessing the level of reactive and personal anxiety } \\
\hline Reactive anxiety & 21,93750 & 15,38462 & 2,50 & 13,59286 & 0,0011 \\
\hline
\end{tabular}

Note: $\mathrm{H}$ - Kruskal-Wallis H-test (one-way ANOVA on ranks), $\mathrm{p}=$ probability value

The analysis showed significant differences between groups with different informational consumption on all psychological charactiristics, except personal anxiety. This supports the idea that personal anxiety is a more stable personal trait. It's a stable tendency to perceive a large range of situations as threatening, that is not changing in pandemic situation, while reactive anxiety essentially depends on the specific situation that causes it.

\section{Discussions}

One of the main goals of this empirical research was to show that informational behavior can be considered as a stress management strategy and a way to adapt to changing or uncertain situations. There was a significant positive correlation between Informational consumption and levels of Tolerance to Ambiguity, Hardiness, Commintment, Control and Challenge and negative correlation with Reactive and Personal Anxiety.

This is in good agreement with the findings of A. Sh. Tkhostov, E. I. Rasskazova, who have studied the correlation of the different types of anxiety of in the pandemic situation with the search for information about coronavirus and with protective actions (Tkhostov and Rasskazova, 2020). The authors identified two aspects in the structure of anxiety about the coronavirus: the fear of the infection and anxiety about negative consequences. Tracking pandemic information is considered a defensive reaction (clarifying information, searching for what reassures or concretizes the threat, giving an action plan) (Tkhostov and Rasskazova, 2020). Described informational behavior strategy has a significant correlation with high level of anxiety (Huang and Zhao, 2020).

Our results have a number of similarities with D. A.Leontiev, E. I. Rasskazova results of studying the connection between subjective well-being with coping strategies and anxiety about coronavirus in the pandemic situation. Emotionally oriented coping strategies associated with a higher level of pandemic anxiety. Problem-oriented and active coping strategies are weakly associated with lower anxiety that could be explained by the lack of effective methods of resolving this new and uncertain situation (Leontiev et all., 2011). In this context, our strategies of informational consumption can be attributed to emotionally oriented coping strategies that assume involving mental avoidance of the problem and finding ways to distract.

This idea supports the previous findings in the literature (Liu, 2020), that COVID-19 information consumption on the Internet and social media during the infectious disease outbreak could elicit intense worry, and in turn increase preventive behaviors by engagement in the COVID-19 preventive actions.

Tull and others examined the impact of COVID-19 and stay-at-home orders on psychological outcomes. The authors have shown that the perceived impact of COVID-19 on daily life was positively 
associated with health anxiety, financial worry, and social support, but negatively associated with loneliness (Tull et al., 2020).

Our results can be supplemented by the findings of some foreign scientists in the field of psychological predictors. Traunmüller et al., (2020) have evaluated the psychological distress in Austria during the initial stage of the COVID-19 outbreak and highlighted the factors making a personality psychologically vulnerable or psychologically protected. Being a female, higher age, lower levels of education, concern about family members, the internet as the main source of information, student or pupil status, poor selfrated health, and the attitude that "there is too much unnecessary worry" were significantly associated with higher psychologically vulnerability. Protective factors were the possibility to work in home office, frequent (indirect) contact with family or friends, the availability of virus-specific information, confidence in the diagnosis capability, and physical activity during the crisis (Traunmüller et al., 2020). Remarkably that informational behavior (the internet as the main source of information) is distinguished as a factor of negative influence on coping the stress. Our results do not support this suggestion, as our respondents indicated increased anxiety after consuming TV-content. Internet content was considered as a more objective and giving more confidence and decreasing the ambiguity of situation.

The findings of C. Traunmüller, R.Stefitz, et al, correlate well with the results of the survey, conducted in China in January-February 2020, studying the levels of psychological impact, anxiety, depression, and stress during the initial stage of the COVID-19 outbreak. Wang et al., (2020) showed that female gender, student status, specific physical symptoms, and poor self-rated health status were significantly associated with a greater psychological impact of the outbreak and higher levels of stress, anxiety, and depression. Specific up-to-date and accurate health information (e.g., treatment, local outbreak situation) and particular precautionary measures (e.g., hand hygiene, wearing a mask) were associated with a lower psychological impact of the outbreak and lower levels of stress, anxiety, and depression (Wang et al., 2020). Getting up-to-date information is highlighted as a factor of decreasing stress and anxiety.

Thus, most researchers agree that the regulation of information consumption and communication can be an effective way to overcome the stress of ambiguity and anxiety in a pandemic situation.

\section{Conclusions}

We have described empirical research of psychological reasons for informational consumption in the COVID-19 pandemic. The findings of this study indicate a significant correlation between informational behavior and psychological characteristics related to coping with stress: tolerance to ambiguity, hardiness, anxiety. We have demonstrated that respondents with increased informational consumption have low or negative scores in Tolerance to Ambiguity, average (but lowest in the sample) values in Hardiness, Commitment, Control, Challenge, and the highest in the sample of Reactive and Personal Anxiety. Respondents with stable informational consumption have average positive scores in Tolerance to Ambiguity, high values in Hardiness, Commitment, Control, and Challenge and a moderate level of Reactive and Personal Anxiety. Respondents with decreased informational consumption showed high levels of Tolerance to Ambiguity, Hardiness, Commitment, Control, and Challenge and low levels of Reactive and Personal Anxiety.

Taken together, these findings suggest that increased informational consumption can be considered as a coping strategy of overcoming the pandemic social isolation for respondents with low hardiness and tolerance to ambiguity: searching different types of information (in particular the latest news about the COVID-19 pandemic) helps such people to overcome the ambiguity of the situation, makes their life more understandable and predictable, thereby giving confidence in the future and making today's interesting. Stable informational consumption indicates that these respondents are stable and confident in their interests, in their need for the information necessary to feel safe. Decreased informational shows that for feeling calm and enjoy the opportunity to spend time on social isolation, these respondents do not need outside information.

\section{Limitations}

Our research has some limitations. We didn't take into account the age and gender characteristics of the respondents, but obviously, informational consumption among representatives of different generations may vary due to different reasons. 
Grishina A. V., \& Abakumova I. V. (2020). Informational behavior in the COVID-19 pandemic: psychological predictors, International Journal of Cognitive Research in Science, Engineering and Education (IJCRSEE), (8), Special issue of Current Research and Trends in Cognitive Sciences 2020, 59-67.

\section{Acknowledgments}

The research was supported by the Russian Foundation for Fundamental Research (Project No. 18-29-22004) (2018) «Psychological and genetic studies of users' behavior predictors that determine the perception of Internet content of various informational orientation».

\section{Conflict of interests}

The authors declare no conflict of interest.

\section{References}

Adorno T. W., Frenkel-Brunswik E., Levinson D. J., \& Sanford R. N. (1950). The Authoritarian Personality. New York: Harper \& Brothers. Retrieved from http://www.ajcarchives.org/main.php?Groupingld=6490

Budner, N. Y. (1962). Intolerance of ambiguity as a personality variable. Journal of personality, 30(1), 29-50. https://doi. org/10.1111/j.1467-6494.1962.tb02303.x

DeRoma, V. M., Martin, K. M., \& Kessler, M. L. (2003). The relationship between tolerance for ambiguity and need for course structure. Journal of instructional psychology, 30(2), 104. Retrieved from https://www.questia.com/library/ journal/1G1-105478978/the-relationship-between-tolerance-for-ambiguity-and

Enikolopov, S. N., Boyko, O. M., Medvedeva, T. I., Vorontsova, O. U., \& Kazmina, O. Y. (2020). Dynamics of psychopathological reaction at the first stage of COVID-19 pandemics. Psychological-Educational Studies, 12(2), 108-126. Retrieved from https://psyjournals.ru/en/psyedu_ej/2020/n2/Enikolopov_et_al.shtml

Enikolopov S. N., \& Kaz'mina O. Yu. (2020). Dynamics of psychopathological reaction at the first stage of COVID-19 pandemics. Psikhologicheskaya gazeta [Psychological Newspaper]. Retrieved from https://www.psy.su/feed/8182/

Freeston, M. H., Tiplady, A., Mawn, L., Bottesi, G., \& Thwaites, S. (2020). Towards a model of uncertainty distress in the context of Coronavirus (Covid-19). The Cognitive Behaviour Therapist, 13, E31. https://doi.org/10.1017/S1754470X2000029X

Frenkel-Brunswik, E. (1948). Tolerance toward ambiguity as a personality variable. American Psychologist, 3(268), 385-401.

Hazen, B. T., Overstreet, R. E., Jones-Farmer, L. A., \& Field, H. S. (2012). The role of ambiguity tolerance in consumer perception of remanufactured products. International Journal of Production Economics, 135(2), 781-790. https://doi. org/10.1016/j.ijpe.2011.10.011

Herman, J. L., Stevens, M. J., Bird, A., Mendenhall, M., \& Oddou, G. (2010). The tolerance for am-biguity scale: Towards a more refined measure for international management research. International Journal of Intercultural Relations, 34(1), 58-65. https://doi.org/10.1016/J.IJINTREL.2009.09.004

Huang Y., \& Zhao N. (2020). Generalized anxiety disorder, depressive symptoms and sleep quality during COVID-19 outbreak in China: a web-based cross-sectional survey. Psychiatry Research, 288. https://doi.org/10.1016/j.psychres.2020.112954

Kajs, L. T., \& McCollum, D. L. (2010). Dealing with ambiguity: Assessment of tolerance for ambiguity in the context of school leadership. Academy of Educational Leadership Journal, 14, 77. Retrived from https://www.questia.com/library/ journal/1G1-241861824/dealing-with-ambiguity-assessment-of-tolerance-for

Kharlamenkova N. E., Bykhovets Yu. V., Dan M. V., \& Nikitina, D. A. (2020). Perezhivanie neopredelennosti, trevogi, bespokoistva $v$ usloviyakh COVID-19 [Experiences of uncertainty, anxiety and unrest during COVID-19] [Elektronnyi resurs]. IP RAS, 2020. Retrieved from http://ipras.ru/cntnt/rus/institut_p/covid-19/kommentarii-eksp/har-1.html?fbclid= IwAR20JC9T6N8XvicF7wz4neKQ8r8Yc3POe8bqmOzG\%20NFaBJqW077L6FBUNnok

Kuzmin M. Yu., Gusev A. N., \& Konopak I. A. (2011). The relationship between gender identity and resilience among female students studying at a university. Bulletin of ZabGU, 11, 58-62. Retrived from https://cyberleninka.ru/article/n/svyazgendernoy-identichnosti-i-zhiznestoykosti-u-studentok-obuchayuschihsya-v-vuze

Leontiev, D. (2019). Happiness and subjective well-being: towards the construction of a conceptual field. The monitoring of public opinion economic \& social changes 1. Retrieved from https://doi.org/10.14515/monitoring.2020.1.02

Leontiev, D., Mandrikova, E., Rasskazova, E., \& Fam, A. (2011). Hardiness as a component of personal potential. Lichnostniy potencial: stryktyra I diagnostika [Personal potential: structure and diagnosis]. Moscow, Meaning. Retrieved from https:// www.hse.ru/data/2013/03/10/1293613146/Леонтьев\%20Мандрикова\%20Рассказова\%20Фам\%202011\%20.. уации $\% 20$ неопределенности $\% 20$ \% 20 выбора.pdf

Litman, J. A. (2010). Relationships between measures of l-and D-type curiosity, ambiguity toler-ance, and need for closure: An initial test of the wanting-liking model of information-seeking. Personality and Individual Differences, 48(4), 397-402. https://doi.org/10.1016/j.paid.2009.11.005

Loginova M. V. (2010) Psychological maintenance of viability of the identity of students [Psikho-logicheskoe soderzhanie zhiznestoikosti lichnosti studentov]. Cand. Diss., 225. Retrived from http://nauka-pedagogika.com/viewer/311197/ a?\#?page=1

Liu, P. L. (2020). COVID-19 Information Seeking on Digital Media and Preventive Behaviors: The Mediation Role of Worry. Cyberpsychology, Behavior, and Social Networking 23(10), 677-682. https://doi.org/10.1089/cyber.2020.0250

Mac Donald, A. P. (1970). Revised Scale for Ambiguity Tolerance: Reliability and Validity. Psychological Reports, 26(3), $791-$ 798. https://doi.org/10.2466/pr0.1970.26.3.791

Maddi, S. R. (2015). Hardiness. The Encyclopedia of Adulthood and Aging, 1-4. https://doi.org/10.1002/9781118521373. wbeaa002

Maddi, S. R., Khoshaba, D. M., Harvey, R. H., Fazel, M., \& Resurreccion, N. (2011). The personality construct of hardiness, $\checkmark$ : Relationships with the construction of existential meaning in life. Journal of Humanistic Psychology, 51(3), 369-388. https://doi.org/10.1177/0022167810388941

Norton, R. W. (1975). Measurement of ambiguity tolerance. Journal of personality assessment, 39(6), 607-619. https://doi. 
Grishina A. V., \& Abakumova I. V. (2020). Informational behavior in the COVID-19 pandemic: psychological predictors, International Journal of Cognitive Research in Science, Engineering and Education (IJCRSEE), (8), Special issue of Current Research and Trends in Cognitive Sciences 2020, 59-67.

org/10.1207/s15327752jpa3906_11

Odintsova M. A. (2015). The psychology of resilience. Moscow: Flint Nauka. Retrieved from http://ppms.edu-penza.ru/ documents/Психология\%20жизнестойкости\%20Учебное\%20пособие.pdf

Rasskazova, E. I., Leontiev, D. A., \& Lebedeva, A. A. (2020). Pandemic as a challenge to subjective well-being: anxiety and coping. Counseling Psychology and Psychotherapy, 28(2). 90-108. https://doi.org/10.17759/cpp.2020280205

Soboleva E. V., \& Shumakova O. A. (2014). The phenomenon of resilience in foreign and domestic research. Sovremennie naychnie issledovania $i$ innovacii [Modern scientific research and innovation]. Retrieved from: http://web.snauka.ru/ issues/2014/05/34519

Spielberger C. D. (1972). Current trends in theory and research. Anxiety-Current trends and theory, 3-19. https://doi. org/10.1016/B978-0-12-657401-2.50008-3

Stankovska G., Memedi I., \& Dimitrovski, D. (2020). Coronavirus COVID-19 disease, mental health and psychosocial support. Society Register, 4(2), 33-48. https://doi.org/10.14746/sr.2020.4.2.03

Tkhostov A. Sh., \& Rasskazova, E. I. (2020). Psychological Contents of Anxiety and the Prevention in an Infodemic Situation: Protection against Coronavirus or the "Vicious Circle" of Anxiety?. Counseling Psychology and Psychotherapy, 28(2), 70-89. https://doi.org/10.17759/cpp.2020280204

Traunmüller, C., Stefitz, R., Gaisbachgrabner, K., \& Schwerdtfeger, A. (2020). Psychological correlates of COVID-19 pandemic in the Austrian population. PREPRINT (Version 1) available at Research Square https://doi.org/10.21203/rs.3.rs-23337/ v1

Trottier, Magan, Wendy Roberts, Irene Drmic, Stephen W. Scherer, Rosanna Weksberg, Cheryl Cytrynbaum, David Chitayat, Cheryl Shuman, and Fiona A. Miller (2013). Parents' perspectives on participating in genetic research in autism. Journal of Autism and Developmental Disorders 43(3), 556-568. https://doi.org/10.1007/s10803-012-1592-y

Tull, M. T., Edmonds, K. A., Scamaldo, K., Richmond, J. R., Rose, J. P., \& Gratz, K. L. (2020). Psychological outcomes associated with stay-at-home orders and the perceived impact of covid-19 on daily life. Psychiatry research, 289, 112098. https://doi.org/10.1016/j.psychres.2020.113098

Våpenstad, E. V. (2010). The ambiguity of the psychoanalytic situation and its relation to the analyst's reverie. Psychoanalytic psychology, 27(4), 513-535. https://doi.org/10.1037/a0020454

Wang, C., Pan, R., Wan, X., Tan, Y., Xu, L., Ho, C. S., \& Ho, R. C. (2020). Immediate psychological responses and associated factors during the initial stage of the 2019 coronavirus disease (COVID-19) epidemic among the general population in China. International journal of environmental research and public health, 17(5), 1729. https://doi.org/10.3390/ ijerph17051729

Zhu, D., Xie, X., \& Xie, J. (2012). When do people feel more risk? The effect of ambiguity tolerance and message source on purchasing intention of earthquake insurance. Journal of Risk Research, 15(8), 951-965. https://doi.org/10.1080/136 69877.2012 .686051 
Grishina A. V., \& Abakumova I. V. (2020). Informational behavior in the COVID-19 pandemic: psychological predictors, International Journal of Cognitive Research in Science, Engineering and Education (IJCRSEE), (8), Special issue of Current Research and Trends in Cognitive Sciences 2020, 59-67. 